\title{
MiR-146b Mediates Endotoxin Tolerance in Human Phagocytes
}

\author{
Tiziana Ada Renzi, ${ }^{1,2}$ Marcello Rubino, ${ }^{1,2}$ Laura Gornati, ${ }^{1,2}$ Cecilia Garlanda, ${ }^{2}$ \\ Massimo Locati, ${ }^{1,2}$ and Graziella Curtale ${ }^{1,2,3}$ \\ ${ }^{1}$ Department of Medical Biotechnologies and Translational Medicine, University of Milan, Milan, Italy \\ ${ }^{2}$ Humanitas Clinical and Research Center, Via Manzoni 113, 20089 Rozzano, Italy \\ ${ }^{3}$ Department of Cancer Biology, The Scripps Research Institute, Jupiter, FL 33458, USA \\ Correspondence should be addressed to Graziella Curtale; gcurtale@scripps.edu
}

Received 11 March 2015; Revised 26 June 2015; Accepted 12 July 2015

Academic Editor: Barbro N. Melgert

Copyright (C) 2015 Tiziana Ada Renzi et al. This is an open access article distributed under the Creative Commons Attribution License, which permits unrestricted use, distribution, and reproduction in any medium, provided the original work is properly cited.

A proper regulation of the innate immune response is fundamental to keep the immune system in check and avoid a chronic status of inflammation. As they act as negative modulators of TLR signaling pathways, miRNAs have been recently involved in the control of the inflammatory response. However, their role in the context of endotoxin tolerance is just beginning to be explored. We here show that miR-146b is upregulated in human monocytes tolerized by LPS, IL-10, or TGF $\beta$ priming and demonstrate that its transcription is driven by STAT3 and RUNX3, key factors downstream of IL-10 and TGF $\beta$ signaling. Our study also found that IFN $\gamma$, known to revert LPS tolerant state, inhibits miR-146b expression. Finally, we provide evidence that miR-146b levels have a profound effect on the tolerant state, thus candidating miR-146b as a molecular mediator of endotoxin tolerance.

\section{Introduction}

Deregulation of the inflammatory response contributes to tissue damage in several pathological conditions, including autoimmune and infectious diseases [1-3]. To balance inflammation, the innate immune system has developed a regulatory mechanism by which innate immune cells, monocytes, and macrophages in particular display reduced response to subsequent challenges after they have been exposed to low concentrations of endotoxin (e.g., LPS) [4, 5], entering in a so-called "tolerant" state. Although endotoxin tolerance has been considered as a protective mechanism to regulate overexuberant inflammation, the incidence of endotoxin tolerance has been associated with high risk of secondary infections and an endotoxin-tolerant state is considered to be a clinical phenomenon observed not only in sepsis $[6,7]$ but also in diseases like acute coronary syndrome [8] and cystic fibrosis $[9,10]$, and in these pathologies the risk of new infections correlates with a refractory state of innate immune cells.

Much of our knowledge on the molecular mechanisms responsible for endotoxin tolerance arises from in vitro studies, where monocytes primed with low doses of LPS or with IL-10 or TGF $\beta$ become tolerant to a subsequent LPS challenging and strongly reduce their production of TNF $\alpha$ and other proinflammatory cytokines [11]. IFN $\gamma$ represents a key negative regulator of LPS tolerance, being able to revert tolerance and restore $\mathrm{TNF} \alpha$ production both in in vitro and in vivo models [12]. The molecular basis of endotoxin tolerance has not been completely elucidated, but it is now clear that it is a dynamic process implying a profound gene reprogramming $[13,14]$. In particular extensive studies demonstrated the impairment of the Toll-like receptor (TLR) signaling pathway at multiple levels, with the consequent repression of proinflammatory mediators (i.e., TNF $\alpha$, IL-6, and IL-12), and the concomitant upregulation of anti-inflammatory molecules, such as IL-10 and TGF $\beta$ [15]. Functionally, tolerant monocytes also exhibit increased phagocytosis due to increased expression of CD64 and impaired antigen presentation ability due to the downregulation of major histocompatibility class II (MHC II), CD86, and class II transactivator (CIITA) [9, 16, 17].

A growing number of miRNAs have been reported to be involved in the regulation of the inflammatory response [18-27], but only recently studies described the differential expression and effects of miRNA in the context of endotoxin 
tolerance $[28,29]$. MiR-146a was the first miRNA described as upregulated in tolerant THP-1 monocytic cells after priming with low dose of LPS and was shown to partially induce LPS desensitization in monocytes [28, 29]. Evidence suggesting a possible role of miR-155 and miR-125b in tolerance has also been reported [30]. It is still unclear to which degree each miRNA contributes to the development of endotoxin tolerance, but of note all these miRNAs have been shown to modulate TLR4 signaling pathway by targeting different components of its signaling cascade [31]. In the present study we show the involvement of miR-146b in the induction of endotoxin tolerance by showing its upregulation in LPS tolerant monocytes, its induction by the anti-inflammatory stimuli IL-10 and TGF $\beta$, and its negative regulation by IFN $\gamma$. We also demonstrate that tuning miR-146b expression results in the induction or reversion of endotoxin tolerance in the THP-1 monocytic cell line.

\section{Materials and Methods}

2.1. Reagents. LPS was from E. coli (serotype 055:B5). IL-10, IL-4, IL-13, and TGF $\beta$ were from R\&D system; IFN $\gamma$ was from Peprotech; dexamethasone was from Sigma Aldrich. Antibodies anti-Pol II (N-20), anti-RUNX3 (H-50), and antiSTAT3 (C-20) for ChIP experiments were purchased from Santa Cruz Biotechnology and anti-Ago2 was purchased from Abcam.

2.2. Cell Purification and Culture. Human monocytes were obtained from healthy donor buffy coats by two-step gradient centrifugation using Ficoll (Biochrom) and Percoll (Amersham) followed by incubation of purified cells in RPMI 1640 (Lonza) without serum for $10 \mathrm{~min}$ at $37^{\circ} \mathrm{C}$ with $5 \% \mathrm{CO}_{2}$. Adherent monocytes were washed twice with PBS and then cultured with RPMI medium supplemented with 10\% FBS and L-glutamine as fully described below. The purity of the monocytes cultures was tested by CD14 staining and flow cytometry analysis, with an average of $90 \% \mathrm{CD}^{+} 4^{+}$cells.

Monocytes and THP-1 cells (ATCC) were grown in RPMI supplemented with $10 \%$ heat-inactivated fetal bovine serum (FBS; Lonza), $100 \mathrm{U} / \mathrm{mL}$ penicillin/streptomycin (Lonza), and $25 \mathrm{mM}$ L-glutamine (Lonza) at $37^{\circ} \mathrm{C}$ with $5 \% \mathrm{CO}_{2}$. HEK293 cells (ATCC) were grown in D-MEM (Cambrex) supplemented with $10 \% \mathrm{FBS}, 100 \mathrm{U} / \mathrm{mL}$ penicillin/streptomycin, and $25 \mathrm{mM} \mathrm{L}$-glutamine at $37^{\circ} \mathrm{C}$ with $5 \% \mathrm{CO}_{2}$.

2.3. Chromatin Immunoprecipitation (ChIP) Assay. ChIP experiments were performed as described elsewhere [32].107 human purified monocytes were culture and extracted DNA was used to perform qPCR using promoter-specific primers [21]. $1 \%$ of starting chromatin was used as input. Signals obtained from the ChIP samples were normalized on those obtained from the corresponding input samples, according to the formula: $100 \times 2^{\wedge \text { (input Ct-sample Ct) }}$. Results were expressed as fold enrichment relative to untreated cells.

2.4. Quantification of miR-146b Expression. Total RNA was purified using TRIzol Reagent (Ambion) and extracted with
“Directzol RNA miniprep" kit (Zymo Research). Q-PCR was conducted using a 7900HT Real-time PCR System. $100 \mathrm{ng}$ of total RNA was reverse transcribed for quantification of $\mathrm{miR}$ expression using TaqMan MiRNA Reverse Transcription kit (Applied Biosystems), according to manufacturer's instructions and as previously described [20,21]. MiRNA expression values were calculated according to the comparative threshold cycle method, using the ubiquitous small nucleolar RNA U6 as endogenous reference.

2.5. Construct Generation. To overexpress miR-146b in THP1 monocytic cells a lentiviral-based system was used, as described elsewhere [21] Briefly, the miR/lentiviral-based expression vector $\mathrm{pRRL}-\mathrm{miR}-146 \mathrm{~b}$ was generated by cloning in the pRRLSIN.cPPT.PGK-GFP.WPRE vector (plasmid \#12252; Addgene) a 500 bp region encompassing the premiR-146b. The lentiviral construct pRRL-ct, encoding for a hairpin yielding a 22-mer RNA with no homology to any human gene, was used as mock construct. THP-1 cells were transduced with pRRL-146b or pRRL-ct vectors and pRRL146b THP-1 GFP ${ }^{+}$cells and pRRL-ct THP1 GFP ${ }^{+}$cells were sorted by FACS with a $90-95 \%$ of purity. To knockdown miR-146b-5p expression, THP-1 cells were transduced with the miRzip lentivector-based construct anti-miR-146b and the relative control (System Biosciences) [21]. Transduced $\mathrm{GFP}^{+}$miRT-146b and GFP ${ }^{+}$miRT-ct THP-1 cells were sorted by FACS with over a $95 \%$ of purity.

2.6. Immunoprecipitation of Ago2-Bound RNAs. Immunoprecipitation of Ago2-bound RNAs (RIP) was performed as previously described [21]. $30 \times 10^{6}$ stimulated monocytes were used and results were expressed as fold enrichment relative to unstimulated samples.

2.7. ELISA Assay. All antibodies and detection reagents were purchased from R\&D Systems. The ELISA was carried out according to the manufacturer's instructions. Samples were diluted so that the optical density fell within the optimal portion of a log standard curve.

2.8. LPS Desensitization and Reversal. MiRT-ct and miRT146b-5p THP1 cells were cultured in 24 -well plates in $500 \mu \mathrm{L}$ RPMI supplemented with $10 \% \mathrm{FBS}$ and $1 \% \mathrm{~L}$-glutamine, incubated or not for $18 \mathrm{~h}$ with $50 \mathrm{ng} / \mathrm{mL} \mathrm{TGF} \beta$ or $20 \mathrm{ng} / \mathrm{mL} \mathrm{IL-10,}$ followed by LPS stimulation with $0.1 \mathrm{ng} / \mathrm{mL}$ or $20 \mathrm{ng} / \mathrm{mL}$ LPS. Cells were then washed twice and challenged with $10 \mathrm{ng} / \mathrm{mL}$ LPS. Supernatants were collected $24 \mathrm{~h}$ after stimulation.

2.9. Statistical Analysis. Statistical evaluation was determined using either Student $t$-test or one-way ANOVA and $p$ values are reported in figures $\left({ }^{*} p<0.05 ;{ }^{* *} p<0.01\right)$.

\section{Results}

3.1. MiR-146b Expression Is Induced by IL-10 and TGF $\beta$ in Human Primary Monocytes. The miR-146 family is composed by miR-146a and miR-146b, both of which are induced 


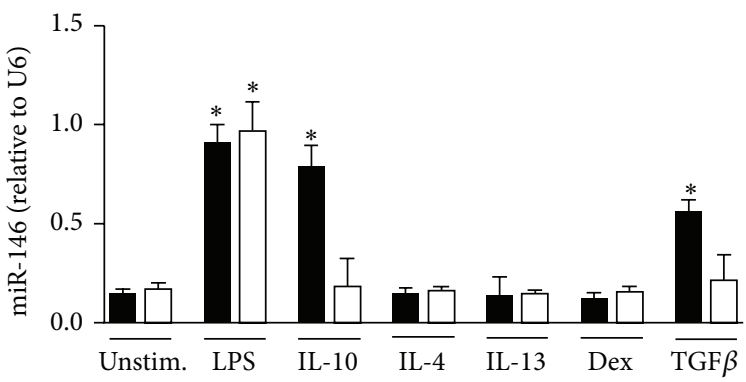

(a)

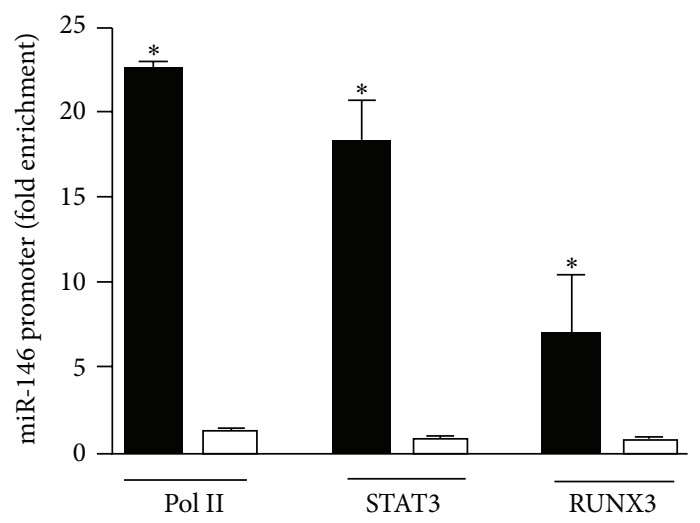

(c)

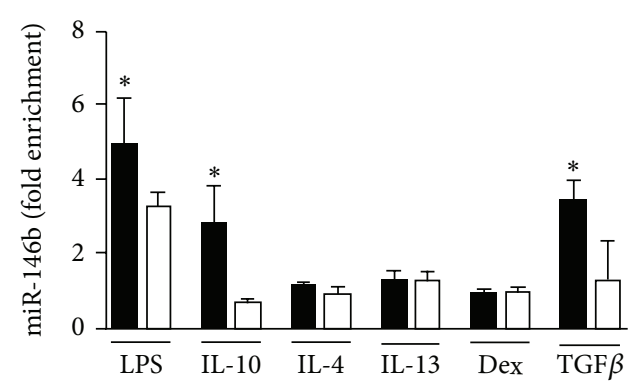

(b)

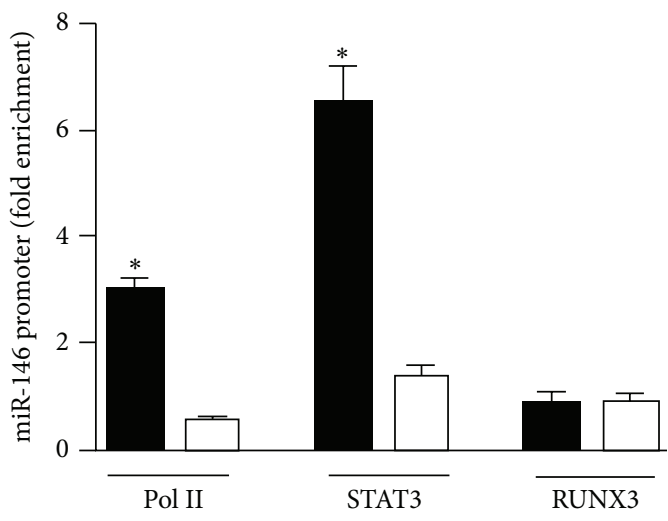

(d)

FIGURE 1: MiR-146b is induced in human monocytes by TGF $\beta$ signaling pathway. Human purified monocytes were stimulated for $24 \mathrm{~h}$ with $100 \mathrm{ng} / \mathrm{mL}$ LPS, $20 \mathrm{ng} / \mathrm{mL}$ IL-10, $20 \mathrm{ng} / \mathrm{mL}$ IL-4, $20 \mathrm{ng} / \mathrm{mL}$ IL-13, $20 \mathrm{ng} / \mathrm{mL}$ Dex, or $50 \mathrm{ng} / \mathrm{mL}$ TGF $\beta$ and (a) miR-146b (black columns) and miR-146a (white columns) levels from total RNA were measured by qPCR in triplicate samples. (b) Cell extracts were subjected to RIP assay using anti-Ago2 or IgG control Abs and levels of miR-146b (black columns) and miR-146a (white columns) were measured by qPCR in triplicate samples. Results are expressed as fold change over control (mean \pm SEM, $n=3$ ). (c-d) ChIP assays were carried out on human purified monocytes stimulated or not for $4 \mathrm{~h}$ with $50 \mathrm{ng} / \mathrm{mL}$ TGF $\beta$ (c) or $20 \mathrm{ng} / \mathrm{mL}$ IL-10 (d) using anti-Pol II, anti-STAT3, or anti-RUNX3 antibodies. Q-PCR was carried out using specific primers for miR-146b (black columns) or miR-146a (white columns) promoters. Results are expressed as fold change over control (mean \pm SEM, $n=3$ ).

during the inflammatory response and target different component of TLR signaling pathway, thus acting as antiinflammatory regulators $[18,21,33]$. In previous studies we reported that LPS induced the expression of both miR-146a and miR-146b in human monocytes [20] and demonstrated that miR-146b but not miR-146a induction was dependent on the endogenous production of IL-10 subsequent to LPS exposure [21]. We here investigated the regulation of miR-146b and miR-146a by anti-inflammatory mediators known to negatively modulate the activation of monocyte/macrophages. We found that, in addition to IL-10, TGF $\beta$ was able to specifically increase the expression of miR-146b but not miR146a. Glucocorticoids (Dex), IL-4, and IL-13 did not affect miR-146b and miR-146a expression levels (Figure 1(a)).

To investigate the functional activity of miR-146b we evaluated its presence into the Ago2-RISC complex and consistent with the expression data we found an enrichment of miR-146b only when monocytes were treated with LPS, IL-10, or TGF $\beta$ (Figure 1(b)). As a control, we measured the relative enrichment of miR-146a and consistent with previous data [21] we detected miR-146a in Ago2-RISC complex only when monocytes were stimulated with LPS (Figure 1(b)).
To elucidate the transcriptional regulation of miR-146b, the cis-regulatory elements in the miR-146b promoter region were characterized. Monocytes exposed to TGF $\beta$ or IL-10 showed an enrichment of Pol II onto the miR-146b promoter but not on miR-146a promoter (Figures $1(\mathrm{c})$ and $1(\mathrm{~d})$ ). Bioinformatic analysis performed on the $1 \mathrm{kbp}$ promoter region of miR-146b showed the presence of two consensus sites for STAT3 and one for RUNX3. Since we previously demonstrated the binding of STAT3 to miR-146b promoter in IL-10 stimulated monocytes [21] (Figure 1(d)) we thought to determine whether STAT3 is also recruited to the miR-146b promoter region upon monocytes TGF $\beta$ stimulation. We found that recruitment of STAT3 is specific to miR-146b but not to miR-146a promoter (Figure 1(c)). Interestingly, STAT3 has been reported to cooperate with RUNX3 [34], which is also directly induced by TGF $\beta$ signaling pathway [35]. Given the proximity of the STAT3 and RUNX3 consensus sites on the miR-146b promoter region, we performed ChIP experiments and found the specific recruitment of RUNX3 transcription factor to the miR-146b promoter region only in monocytes challenged with TGF $\beta$ (Figures $1(\mathrm{c})$ and $1(\mathrm{~d})$ ). Taken together, these data identify miR-146b as an IL-10- and 


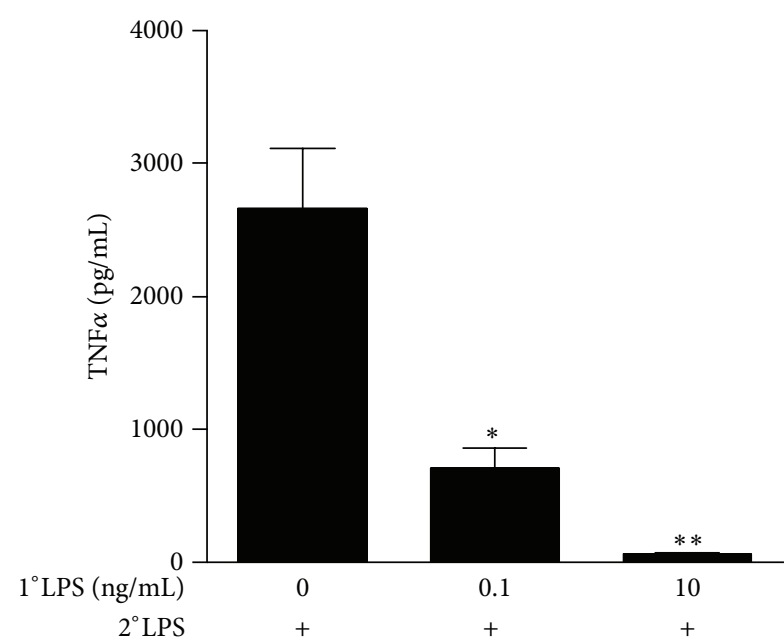

(a)

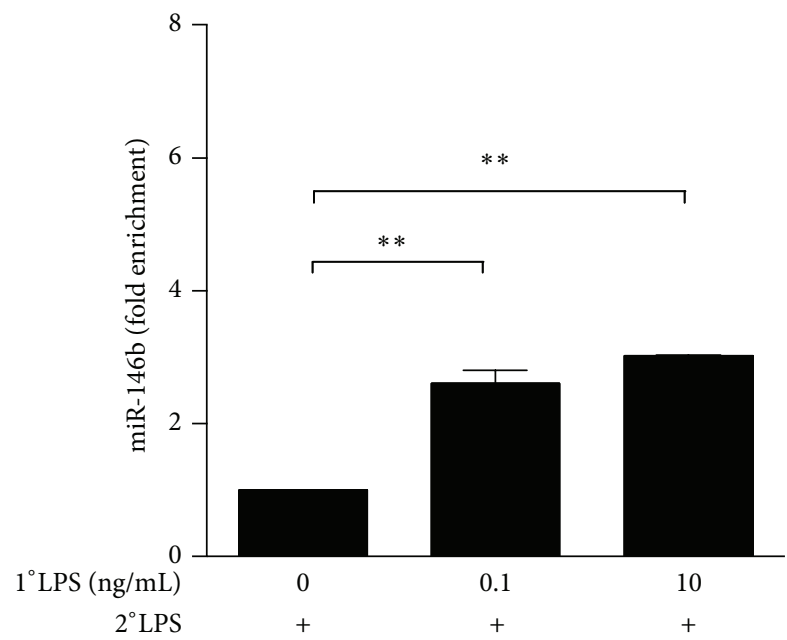

(b)

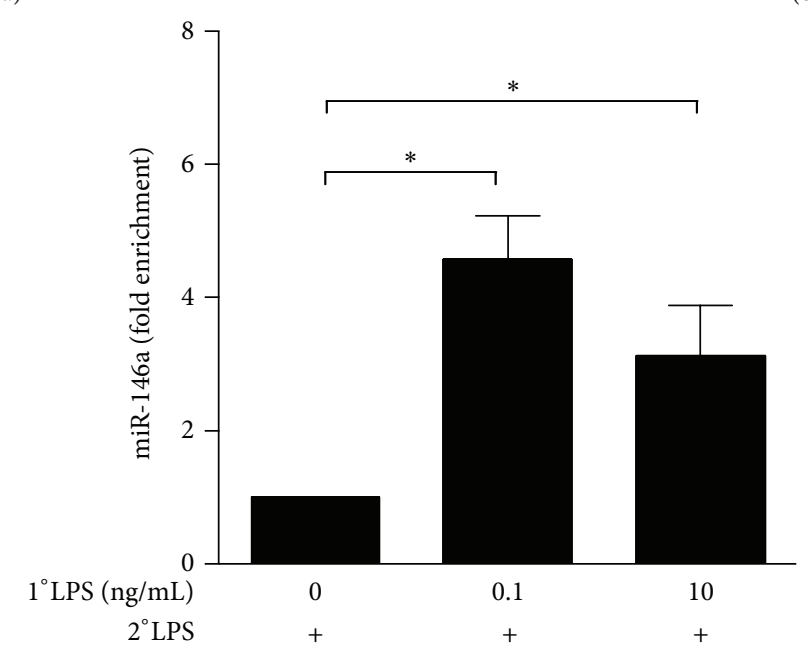

(c)

FIGURE 2: miR-146b and miR-146a are induced in endotoxin tolerized monocytes. Monocytes were first primed with $0,0.1$, or $10 \mathrm{ng} / \mathrm{mL}$ LPS $\left(1^{\circ} \mathrm{LPS}\right)$ for $18 \mathrm{~h}$ and then challenged for $24 \mathrm{~h}$ with $10 \mathrm{ng} / \mathrm{mL}$ LPS $\left(2^{\circ} \mathrm{LPS}\right)$. After $24 \mathrm{~h}$ stimulation, TNF $\alpha$ levels (a) were measured by ELISA in cell-free supernatants, and levels of (b) miR-146b and (c) miR-146a were assayed by qPCR in triplicate samples, normalized relative to U6, and expressed as fold enrichment as compared to unstimulated samples. Results are expressed as mean \pm SEM of three independent experiments.

TGF $\beta$-responsive gene, whose expression in monocytes is specifically driven by STAT3 in response to IL-10 and by STAT3 and RUNX3 in response to TGF $\beta$.

\section{2. miR-146b Is Induced in Endotoxin Tolerized Human} Monocytes. Since miR-146a was shown to be involved in LPS tolerance $[28,29]$ and we previously demonstrated that miR-146b is a negative regulator of TLR signaling [21], we investigated the role of miR-146b in the induction of LPS tolerance. We found $\mathrm{TNF} \alpha$ strongly downregulated in in vitro tolerized monocytes (Figure 2(a)), in agreement with previous reports [36]. Interestingly, the decrease of $\mathrm{TNF} \alpha$ levels was proportional to the dose of LPS used to prime cells: its expression was dramatically impaired in monocytes primed with $0.1 \mathrm{ng} / \mathrm{mL}$ LPS and completely abolished with $10 \mathrm{ng} / \mathrm{mL}$ LPS (Figure 2(a)). Next we analyzed miR-146b expression levels in tolerized monocytes, using miR-146a as positive control [28]. Strikingly, both miR-146b and miR-146a showed significant higher expression in tolerized monocytes compared to untolerized control cells (Figures 2(b) and 2(c), resp.), thus suggesting miR-146b putative role in LPS tolerance.

3.3. IL-10 and TGF $\beta$ Priming Induced Tolerance in Human Monocytes and LPS Responsiveness Can Be Restored by IFN $\gamma$ Pretreatment. IL-10 and TGF $\beta$ act as feedback inhibitors of the LPS-mediated inflammatory response and are part of a more complex network of regulation in which IFN $\gamma$ operates an opposite function working as a coactivator of the inflammatory pathway triggered by LPS [37]. It has also been reported that IFN $\gamma$ is able to revert LPS tolerance both in human $[11,38]$ and murine $[39,40]$ phagocytes. Accordingly, in human monocytes IFN $\gamma$ pretreatment strongly enhanced LPS-dependent induction of TNF $\alpha$ and significantly impaired LPS-dependent tolerization effect (Figure 3(e)). Interestingly, IFN $\gamma$ was able to inhibit 


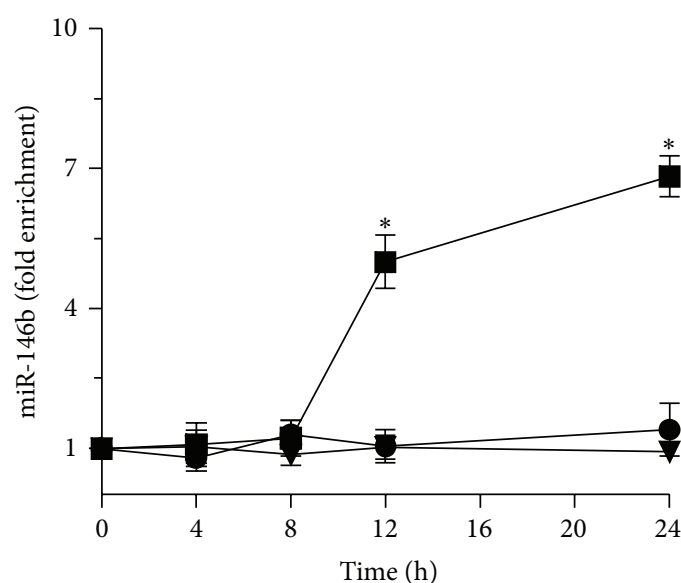

(a)

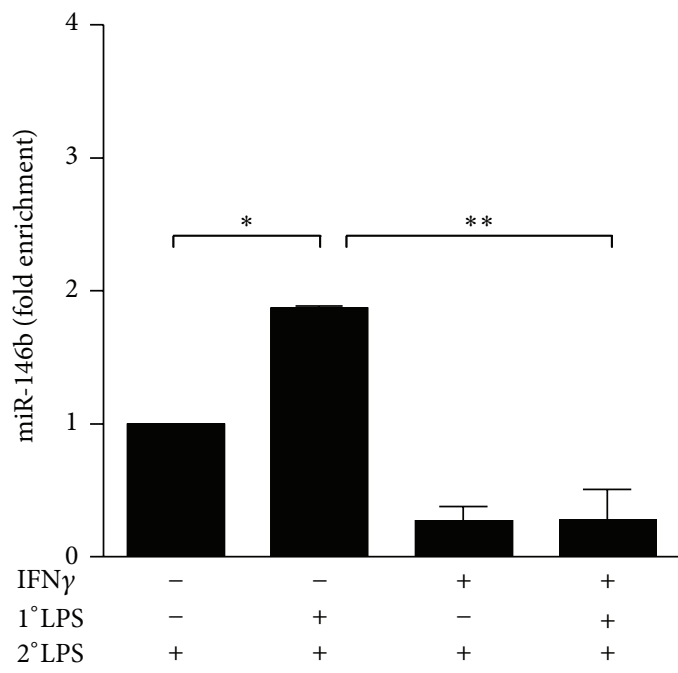

(c)

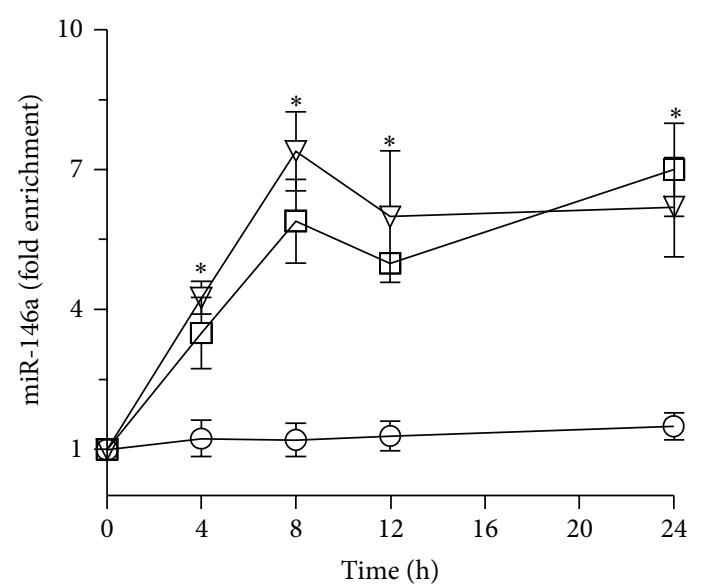

(b)

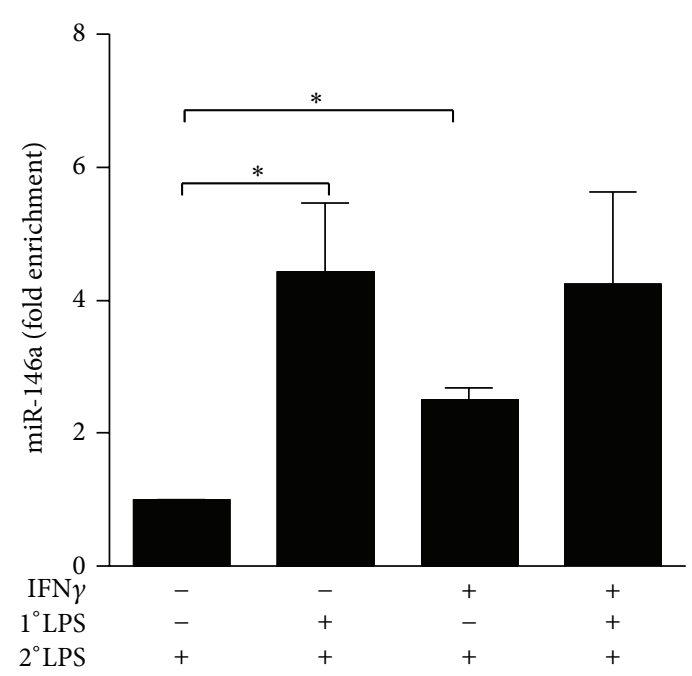

(d)

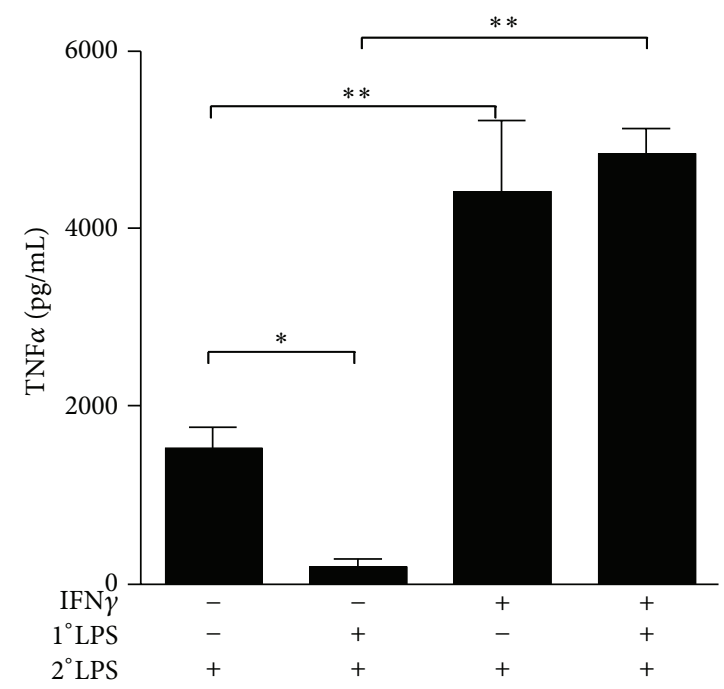

(e)

FIGURE 3: IFN $\gamma$ inhibits the upregulation of miR-146b in tolerized monocytes. (a and b) Monocytes were cultured for the indicated times with $100 \mathrm{ng} / \mathrm{mL}$ LPS (circle), $20 \mathrm{ng} / \mathrm{mL}$ IFN $\gamma$ (square), or both stimuli (triangle). (a) MiR-146b and (b) miR-146a were quantified by qPCR. (c to e) Human purified monocytes pretreated or not with $10 \mathrm{ng} / \mathrm{mL}$ IFN $\gamma$, primed with $0.1 \mathrm{ng} / \mathrm{mL}$ LPS ( $1^{\circ}$ LPS) for $18 \mathrm{~h}$, and then challenged with $10 \mathrm{ng} / \mathrm{mL}$ LPS ( $\left.2^{\circ} \mathrm{LPS}\right)$. After $24 \mathrm{~h}$ stimulation levels of (c) miR-146b and (d) miR-146a were assayed by qPCR in triplicate samples, normalized relative to U6, and expressed as fold enrichment as compared to unstimulated samples. (e) TNF $\alpha$ levels were measured by ELISA in cell-free supernatants. Results are expressed as mean \pm SEM of three independent experiments. 


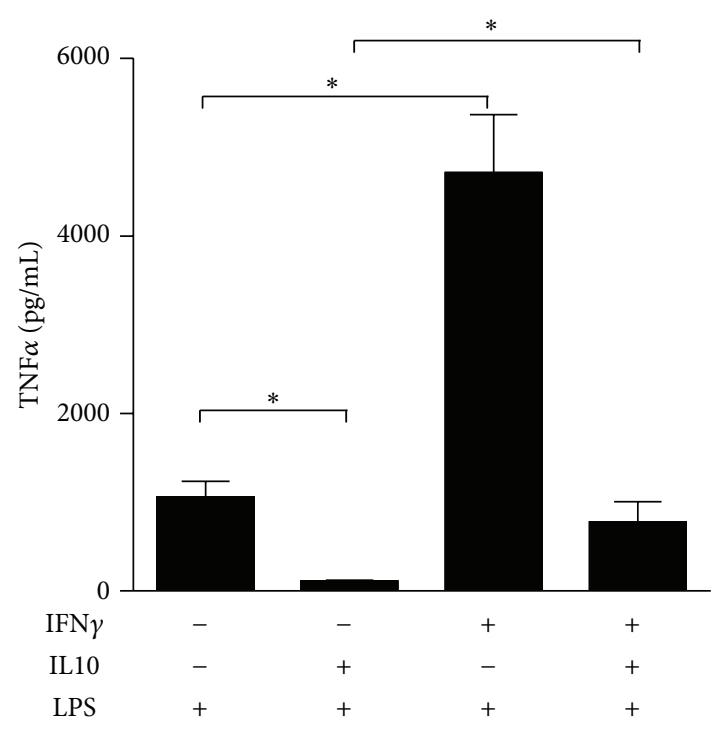

(a)

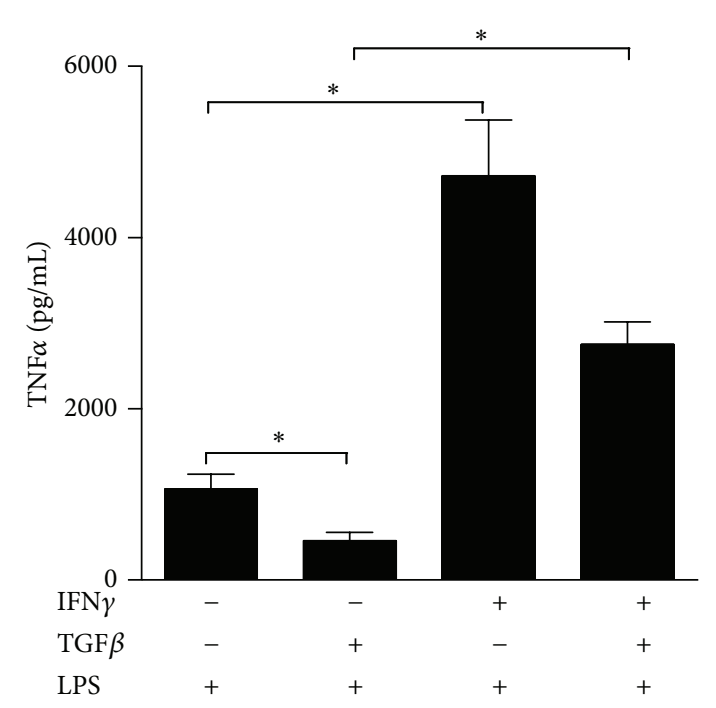

(b)

FIGURE 4: Inhibitory role of IFN $\gamma$ on IL-10- and TGF $\beta$-dependent endotoxin tolerance. Monocytes were pretreated or not with $10 \mathrm{ng} / \mathrm{mL}$ IFN $\gamma$ and primed with $10 \mathrm{ng} / \mathrm{mL}$ IL-10 (a) or $50 \mathrm{ng} / \mathrm{mL}$ TGF $\beta$ (b) for $18 \mathrm{~h}$ and then stimulated with $10 \mathrm{ng} / \mathrm{mL}$ LPS. Supernatants were collected $24 \mathrm{~h}$ later; TNF $\alpha$ protein levels were quantified by ELISA. Results are expressed as mean \pm SEM of three independent experiments.

the LPS-dependent induction of miR-146b when monocytes were challenged with both LPS and IFN $\gamma$ (Figure 3(a)), whereas it did not affect the expression of miR-146a (Figure 3(b)). Moreover, pretreatment with IFN $\gamma$ completely abolished the increased expression of miR-146b observed in LPS-tolerized monocytes, but it had no effect on the overexpression of miR-146a observed in tolerized monocytes (Figures 3(c) and 3(d), resp.).

Opposite to IFN $\gamma$, the anti-inflammatory cytokines IL-10 and TGF $\beta$ support LPS desensitization and have been experimentally used to induce hyporesponsiveness to LPS [11]. Both stimuli decreased the expression of TNF $\alpha$ induced by a following stimulation with LPS. IFN $\gamma$ pretreatment, which strongly enhanced LPS-dependent induction of inflammatory cytokines, was also able to impair the IL-10- and TGF $\beta$ dependent tolerization effect (Figures 4(a) and 4(b)). Since we have observed that both IL-10 and TGF $\beta$ induce the expression of miR-146b (Figure 1(c)), altogether these data candidate miR-146b as an effector of LPS tolerance.

3.4. Upregulation of miR-146b Mimics LPS Priming to Induce Endotoxin Tolerance. To determine the role of miR-146b in endotoxin tolerance, we used the THP-1 monocytic cell line, a well-established model for in vitro study of endotoxin tolerance. We showed that both miR-146b and miR-146a were significantly induced by LPS (Figure 5(a)). This data were consistent with the expression data of miR-146b and miR$146 \mathrm{a}$ in human primary monocytes. In order to discriminate the relative contribution of miR-146b to the establishment of the endotoxin tolerance phenotype, we transduced THP-1 monocytic cells with lentiviral vectors to specifically overexpress (pRRL-146b THP-1 cells) or inhibit miR-146b isoform (miRT-146b THP-1 cells) without affecting miR146a expression (Figures 5(b)-5(d)). As shown in Figure 5(e),
pRRL-146b THP-1 cells stimulated with a single dose of LPS exhibited lower levels of TNF $\alpha$ as compared to pRRL-ct THP1 cells, thus inducing a state of hyporesponsiveness to LPS similar to that observed by the subsequent LPS stimulation. Accordingly, the induction of endotoxin tolerance by priming monocytes with LPS, IL-10, or TGF $\beta$ was completely abolished when the endogenous miR-146b expression was inhibited (Figure 5(f)). Therefore, LPS responsiveness was restored in all the three different in vitro model of endotoxin tolerance, demonstrating that miR-146b is induced during LPS tolerance as part of the inhibitory feedback mechanism that take place in monocytes to render cells refractory to subsequent LPS challenge. Figure 6 depicts the proposal model of miR-146b and miR-146a effect on induction of endotoxin tolerance.

\section{Discussion}

Deregulation of the inflammatory response contributes to tissue damage in pathological conditions such as autoimmune diseases and cancer $[3,41,42]$. The innate immune system has developed a number of mechanisms, such as endotoxin tolerance, to balance inflammation. Endotoxin tolerance is a complex, orchestrated counter-regulatory response to inflammation, during which monocytes undergo a global transcriptional and functional reprogramming and enter into a refractory state, unresponsive to a subsequent LPS challenge. A characteristic feature of endotoxin tolerance is the downregulation of several proinflammatory genes and the concomitant upregulation of some anti-inflammatory genes [43]. In particular, the induction of IL-10 and TGF $\beta$ in the late phase of the inflammatory response represents a key step for the induction of endotoxin tolerance [16, 21, 44] leading to leukocyte deactivation through the impairment of TLR 


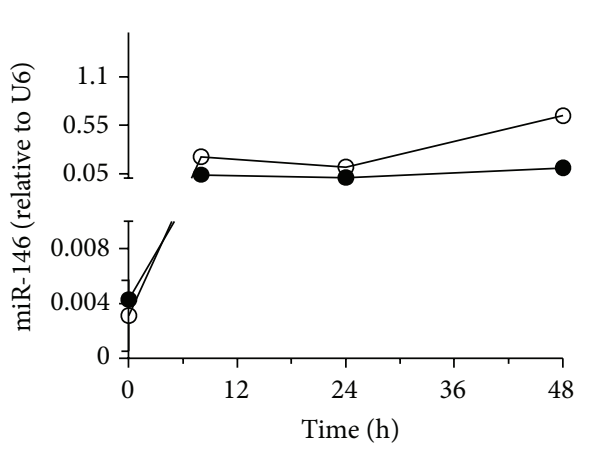

(a)

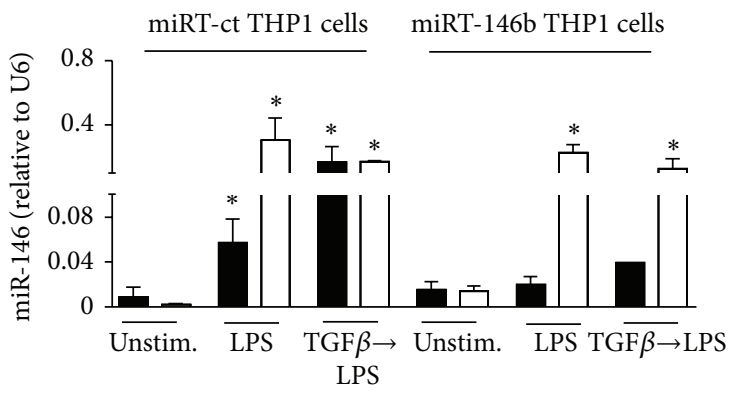

(c)

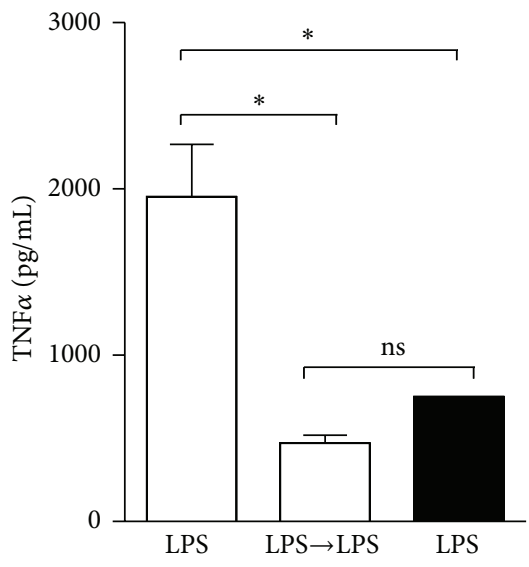

(e)

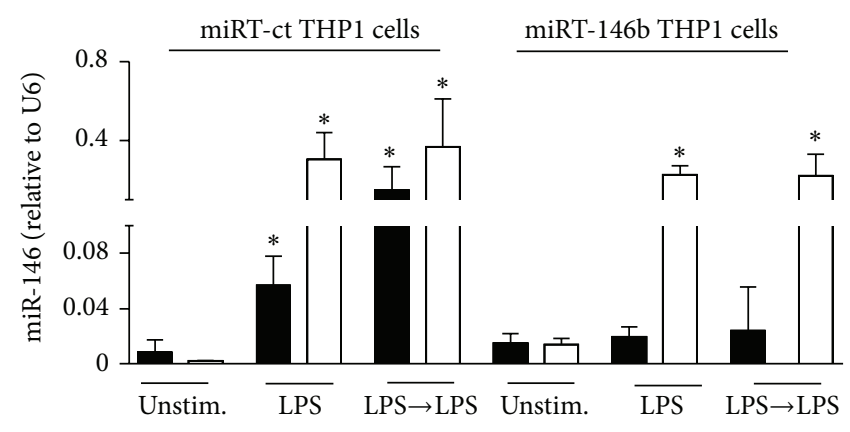

(b)

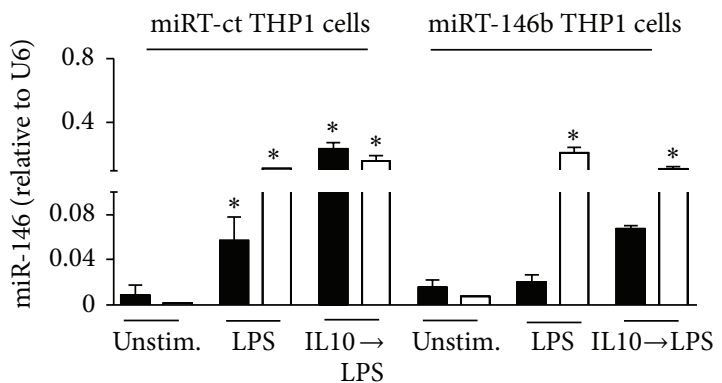

(d)

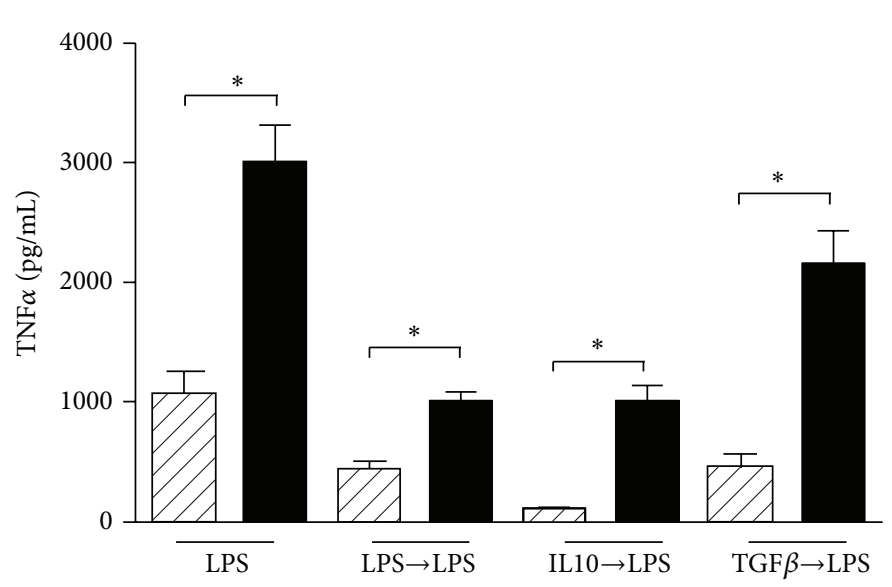

(f)

FIGURE 5: (a) THP-1 wild-type cells were stimulated for the indicated times with $1 \mu \mathrm{g} / \mathrm{mL}$ of LPS. MiR-146b (black circles) and miR-146a (white circles) were measured by qPCR and their levels were normalized relative to U6. (b-d) miRT-ct and miRT-146b THP-1 cells were primed or not with $100 \mathrm{ng} / \mathrm{mL}$ LPS (b), $20 \mathrm{ng} / \mathrm{mL}$ IL-10 (c), or $50 \mathrm{ng} / \mathrm{mL}$ TGF $\beta$ (d) for $18 \mathrm{~h}$ and then challenged with $1 \mathrm{ug} / \mathrm{mL}$ LPS for $24 \mathrm{~h}$. MiR-146b (black columns) and miR-146a (white columns) were measured by qPCR and normalized to U6 levels. (e) TNF $\alpha$ protein levels were measured by ELISA in cell-free supernatants of pRRL-ct (white columns) or pRRL-146b (black columns) THP-1 cells primed or not with 100 $\mathrm{ng} / \mathrm{ml}$ LPS and stimulated with $1 \mathrm{ug} / \mathrm{mL}$ LPS. (f) miRT-ct (white columns) and miRT-146b (black columns) THP-1 cells were primed or not with $100 \mathrm{ng} / \mathrm{mL}$ LPS, $20 \mathrm{ng} / \mathrm{mL}$ IL-10, or $50 \mathrm{ng} / \mathrm{mL}$ TGF $\beta$ for $18 \mathrm{~h}$ and then challenged with $1 \mathrm{ug} / \mathrm{mL}$ LPS for $24 \mathrm{~h}$. TNF $\alpha$ protein levels were quantified by ELISA. Results are expressed as mean \pm SEM of three independent experiments.

signaling. Defects of TLR4 signaling have been observed at the level of the receptor, adaptors, transcription factors, and signaling molecules. In this regard, recent studies have focus attention on the differential expression and effects of miRNA in the modulation of TLR4 signaling in monocytes [18-20] and interestingly, new evidence suggests the involvement of miRNA in the regulation of key components of TLR4 pathway during endotoxin tolerance $[28,29]$.
The miR-146 family, composed by miR-146a and miR$146 \mathrm{~b}$, has been implicated in the regulation of immune cell signaling $[45,46]$ and more interestingly in the modulation of the inflammatory response in monocytes $[18,21,22]$. In particular, miR-146a was shown to be involved in LPS response and in endotoxin tolerance; recent clinical studies showed increased expression of miR-146a in monocytes isolated from CLL patients, challenged with LPS ex vivo [47]. 


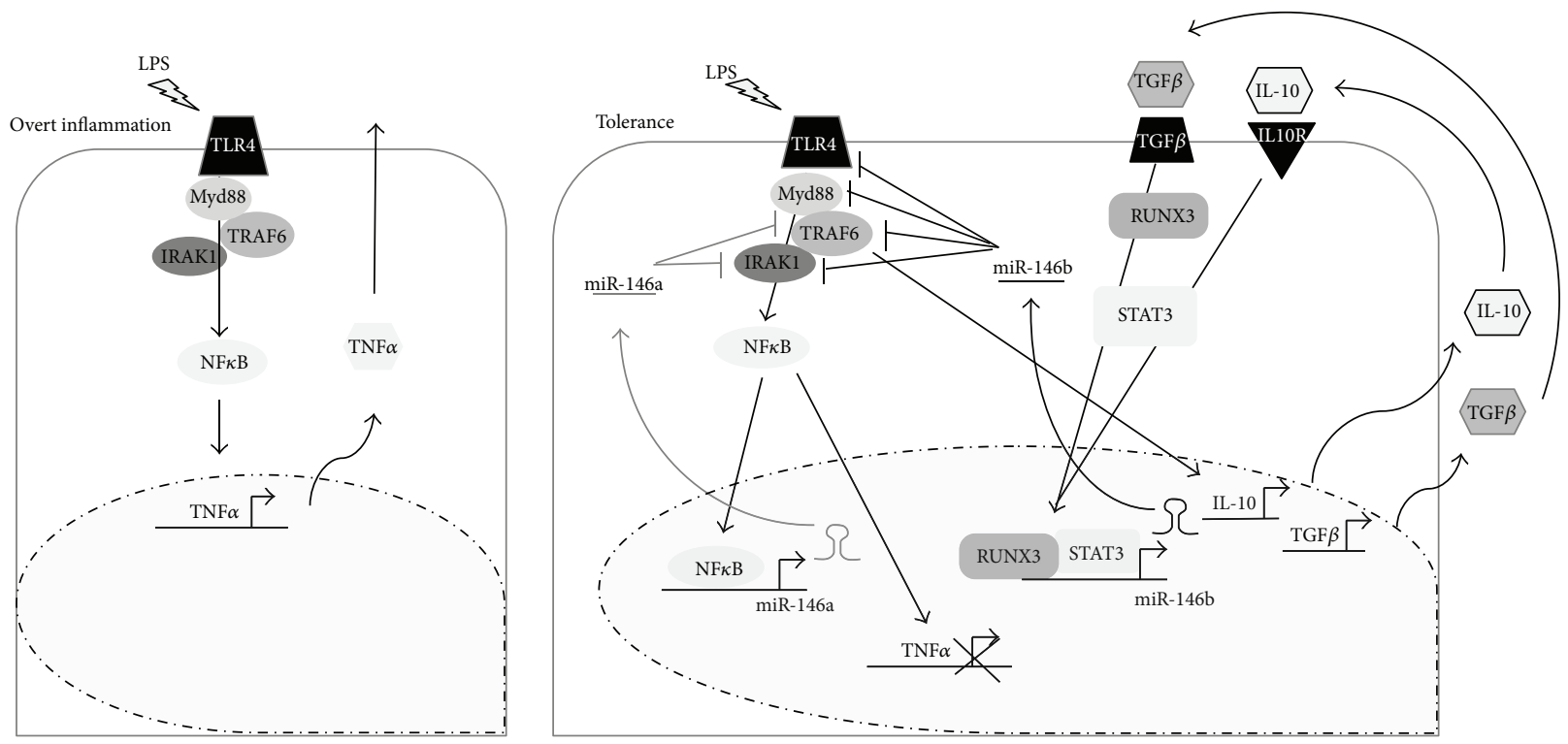

FIGURE 6: MiR-146 a/b effect on induction of endotoxin tolerance. During overt inflammation activation of the TLR4 signaling pathway triggers the induction of proinflammatory cytokines, including TNF $\alpha$, IL-6, CCL3, and IL-12. In the late phase of the inflammatory response, the induction of anti-inflammatory genes, including IL-10 and TGF $\beta$, drives the expression of miR-146b through STAT3 and RUNX3, which negatively modulate TLR pathway at different steps, thus inducing tolerance.

A correlation between miR-146a gene polymorphisms and the risk of severe sepsis has also been described [48]. Despite these first studies highlighting the important role of miR146a in endotoxin tolerance, the possible contribution of miR$146 \mathrm{~b}$ in the regulation of the LPS response has not yet been addressed potentially based on the report by Taganov et al. [18], indicating that miR-146a was the major miRNA of the miR-146 family induced by LPS in THP-1 monocytes.

We previously described miR-146b as the other miR-146 family member able to negatively modulate the inflammatory response in phagocytes by targeting multiple components of the TLR signaling pathway [21]. Since defects in TLR signaling and in the consequent release of proinflammatory cytokines are characteristics of endotoxin tolerance, we thought to shed light on the potential role of miR-146b in the induction of the tolerant state. We first demonstrate that both miR-146b and miR-146a are expressed in LPSstimulated human primary monocytes and in THP-1 monocytic cells. Secondly, their expression is induced in LPStolerized monocytes. Since both miRNAs are abundantly expressed in this cellular context and have overlapping target genes, to discriminate the relative contribution of miR-146b to the establishment of the endotoxin tolerance phenotype, we transduced THP-1 cells with a miR-146b lentiviral vector, which specifically inhibits miR-146b isoform without affecting miR-146a expression. We found that inhibition of endogenous miR-146b levels in LPS tolerized cells completely restored the levels of $\mathrm{TNF} \alpha$ protein, here used as readout of endotoxin tolerance. Accordingly, the enforced expression of miR-146b in THP-1 monocytes mimicked the effects of LPS priming, inducing a state of tolerance comparable to that observed by the sequential stimulation with LPS in control cells. Remarkably, miR-146b but not miR-146a expression levels were further induced by LPS when monocytes were primed with TGF $\beta$ - and IL-10-tolerized monocytes and this is consistent with the specific upregulation of miR-146b in anti-inflammatory conditions. Indeed, characterization of miR-146b transcriptional regulation by bioinformatics analysis and ChIP experiments showed that RUNX3, an important mediator of TGF $\beta$ signaling, is specifically recruited to miR$146 \mathrm{~b}$ promoter in monocytes challenged with $\mathrm{TGF} \beta$, while STAT3 drives the expression of miR-146b in both TGF $\beta$ and IL-10 stimulated monocytes. It is known that IFN $\gamma$ can prevent or revert endotoxin tolerance through the inhibition of TGF $\beta$ and IL-10 signaling [37], although the precise molecular mechanism responsible for IFN $\gamma$-dependent negative feedback loop is still incompletely elucidated. Importantly, the direct induction of miR-146b by IL-10 or TGF $\beta$ as well as its indirect induction after LPS challenge was completely abolished by IFN $\gamma$.

Altogether our data propose miR-146b as a key antiinflammatory miRNA, which acts together with miR-146a in mediating endotoxin tolerance. Notably, we demonstrated a differential regulation of miR-146b and miR-146a expression, suggesting that miR- $146 \mathrm{~b}$ could be one of the molecular tools used by IL-10 and TGF $\beta$ to induce an LPS refractoriness state. We also suggest that the two miR-146 family members may represent the components of a relay team in which the two isoforms succeed each other to control expression of proinflammatory genes. Although the observed miR-146b effect in the induction of endotoxin tolerance is consistent with the previously shown regulation of the TLR signaling pathway by miR-146b [21], it is known that endotoxin tolerance is a more complex process, involving a wider cellular regulation. Other biological processes, such as phagocytosis or antigen presentation, should be investigated in in vivo 
models of endotoxin tolerance to shed light on the effective impact of miR-146b and miR-146a deregulation in the context of endotoxin tolerance. Moreover, due to the large clinical implications of endotoxin tolerance it would be interesting to test the impact of miR-146b deregulation in a clinical context. Further investigations covering all these aspects are needed to candidate miR-146b as a possible therapeutic tool for treating several clinical conditions, such as sepsis and other inflammatory-related disorders.

\section{Conflict of Interests}

All authors disclose any commercial affiliations or consultancies, stock or equity interests, or patent-licensing arrangements that could be considered to pose a conflict of interests regarding the submitted paper.

\section{Acknowledgments}

The authors thank Dr. S. Moleirinho for her help in editing and proofreading the paper. This study was supported by research grants from the European Community's Seventh Framework Program [FP7-2007-2013] under grant agreement HEALTH-F4-2011-281608 (TIMER), Ministero dell'Istruzione dell'Università e della Ricerca (PRIN Project 2009JP9WTS_002; FIRB project RBFR08CW8G), the Italian Association for Cancer Research (AIRC), and Fondazione Cariplo.

\section{References}

[1] C. N. Serhan, S. D. Brain, C. D. Buckley et al., "Resolution of inflammation: State of the art, definitions and terms," The FASEB Journal, vol. 21, no. 2, pp. 325-332, 2007.

[2] P. Libby, "Inflammation in atherosclerosis," Arteriosclerosis, Thrombosis, and Vascular Biology, vol. 32, no. 9, pp. 2045-2051, 2045.

[3] H. Lu, W. Ouyang, and C. Huang, "Inflammation, a key event in cancer development," Molecular Cancer Research, vol. 4, no. 4, pp. 221-233, 2006.

[4] E. López-Collazo and C. del Fresno, "Pathophysiology of endotoxin tolerance: mechanisms and clinical consequences," Critical Care, vol. 17, no. 6, article 242, 2013.

[5] D. Schilling, K. Thomas, K. Nixdorff, S. N. Vogel, and M. J. Fenton, "Toll-like receptor 4 and Toll-IL-1 receptor domaincontaining adapter protein (TIRAP)/myeloid differentiation protein 88 adapter-like (Mal) contribute to maximal IL-6 expression in macrophage," The Journal of Immunology, vol. 169, no. 10, pp. 5874-5880, 2002.

[6] P. Escoll, C. Del Fresno, L. García et al., "Rapid up-regulation of IRAK-M expression following a second endotoxin challenge in human monocytes and in monocytes isolated from septic patients," Biochemical and Biophysical Research Communications, vol. 311, no. 2, pp. 465-472, 2003.

[7] J.-M. Cavaillon, C. Adrie, C. Fitting, and M. Adib-Conquy, "Reprogramming of circulatory cells in sepsis and SIRS," Journal of Endotoxin Research, vol. 11, no. 5, pp. 311-320, 2005.

[8] C. del Fresno, L. Soler-Rangel, A. Soares-Schanoski et al., "Inflammatory responses associated with acute coronary syndrome up-regulate IRAK-M and induce endotoxin tolerance in circulating monocytes," Journal of Endotoxin Research, vol. 13, no. 1, pp. 39-52, 2007.

[9] C. del Fresno, F. García-Rio, V. Gómez-Piña et al., "Potent phagocytic activity with impaired antigen presentation identifying lipopolysaccharide-tolerant human monocytes: demonstration in isolated monocytes from cystic fibrosis patients," The Journal of Immunology, vol. 182, no. 10, pp. 6494-6507, 2009.

[10] C. del Fresno, V. Gómez-Piña, V. Lores et al., "Monocytes from cystic fibrosis patients are locked in an LPS tolerance state: down-regulation of TREM-1 as putative underlying mechanism," PLoS ONE, vol. 3, no. 7, Article ID e2667, 2008.

[11] F. Randow, U. Syrbe, C. Meisel et al., "Mechanism of endotoxin desensitization: involvement of interleukin 10 and transforming growth factor $\beta$," The Journal of Experimental Medicine, vol. 181, no. 5, pp. 1887-1892, 1995.

[12] M. Schröder, C. Meisel, K. Buhl et al., "Different modes of IL10 and TGF-beta to inhibit cytokine-dependent IFN-gamma production: consequences for reversal of lipopolysaccharide desensitization," The Journal of Immunology, vol. 170, no. 10, pp. 5260-5267, 2003.

[13] S. L. Foster and R. Medzhitov, "Gene-specific control of the TLR-induced inflammatory response," Clinical Immunology, vol. 130, no. 1, pp. 7-15, 2009.

[14] J.-M. Cavaillon and M. Adib-Conquy, "Bench-to-bedside review: endotoxin tolerance as a model of leukocyte reprogramming in sepsis," Critical Care, vol. 10, no. 5, article 233, 2006.

[15] S. K. Biswas and E. Lopez-Collazo, "Endotoxin tolerance: new mechanisms, molecules and clinical significance," Trends in Immunology, vol. 30, no. 10, pp. 475-487, 2009.

[16] G. Monneret, M.-E. Finck, F. Venet et al., "The antiinflammatory response dominates after septic shock: association of low monocyte HLA-DR expression and high interleukin-10 concentration," Immunology Letters, vol. 95, no. 2, pp. 193-198, 2004.

[17] J. Manjuck, D. C. Saha, M. Astiz, L.-J. Eales, and E. C. Rackow, "Decreased response to recall antigens is associated with depressed costimulatory receptor expression in septic critically ill patients," Journal of Laboratory and Clinical Medicine, vol. 135, no. 2, pp. 153-160, 2000.

[18] K. D. Taganov, M. P. Boldin, K.-J. Chang, and D. Baltimore, "NF$\kappa \mathrm{B}$-dependent induction of microRNA miR-146, an inhibitor targeted to signaling proteins of innate immune responses," Proceedings of the National Academy of Sciences of the United States of America, vol. 103, no. 33, pp. 12481-12486, 2006.

[19] R. M. O’Connell, K. D. Taganov, M. P. Boldin, G. Cheng, and D. Baltimore, "MicroRNA-155 is induced during the macrophage inflammatory response," Proceedings of the National Academy of Sciences of the United States of America, vol. 104, no. 5, pp. 16041609, 2007.

[20] M. Rossato, G. Curtale, N. Tamassia et al., "IL-10-induced microRNA-187 negatively regulates TNF-alpha, IL-6, and IL12 p40 production in TLR4-stimulated monocytes," Proceedings of the National Academy of Sciences of the United States of America, vol. 109, no. 45, pp. E3101-E3110, 2012.

[21] G. Curtale, M. Mirolo, T. A. Renzi, M. Rossato, F. Bazzoni, and M. Locati, "Negative regulation of Toll-like receptor 4 signaling by IL-10-dependent microRNA-146b," Proceedings of the National Academy of Sciences of the United States of America, vol. 110, no. 28, pp. 11499-11504, 2013.

[22] J. L. Zhao, D. S. Rao, M. P. Boldin, K. D. Taganov, R. M. O'Connell, and D. Baltimore, "NF-kappaB dysregulation 
in microRNA-146a-deficient mice drives the development of myeloid malignancies," Proceedings of the National Academy of Sciences of the United States of America, vol. 108, no. 22, pp. 9184-9189, 2011.

[23] R. M. O'Connell, A. A. Chaudhuri, D. S. Rao, and D. Baltimore, "Inositol phosphatase SHIP1 is a primary target of miR-155," Proceedings of the National Academy of Sciences of the United States of America, vol. 106, no. 17, pp. 7113-7118, 2009.

[24] J. Hou, P. Wang, L. Lin et al., "MicroRNA-146a feedback inhibits RIG-I-dependent type I IFN production in macrophages by targeting TRAF6, IRAK1, and IRAK2," The Journal of Immunology, vol. 183, no. 3, pp. 2150-2158, 2009.

[25] R.-S. Huang, G.-Q. Hu, B. Lin, Z.-Y. Lin, and C.-C. Sun, "Microrna-155 silencing enhances inflammatory response and lipid uptake in oxidized low-density lipoprotein-stimulated human THP-1 macrophages," Journal of Investigative Medicine, vol. 58, no. 8, pp. 961-967, 2010.

[26] C. E. McCoy, F. J. Sheedy, J. E. Qualls et al., "IL-10 inhibits miR155 induction by toll-like receptors," The Journal of Biological Chemistry, vol. 285, no. 27, pp. 20492-20498, 2010.

[27] G. Liu, A. Friggeri, Y. Yang, Y.-J. Park, Y. Tsuruta, and E. Abraham, "miR-147, a microRNA that is induced upon toll-like receptor stimulation, regulates murine macrophage inflammatory responses," Proceedings of the National Academy of Sciences of the United States of America, vol. 106, no. 37, pp. 15819-15824, 2009.

[28] M. A. Nahid, K. M. Pauley, M. Satoh, and E. K. L. Chan, "miR146a is critical for endotoxin-induced tolerance: implication in innate immunity," The Journal of Biological Chemistry, vol. 284, no. 50, pp. 34590-34599, 2009.

[29] M. A. Nahid, M. Satoh, and E. K. L. Chan, "Mechanistic role of microRNA-146a in endotoxin-induced differential crossregulation of TLR signaling," Journal of Immunology, vol. 186, no. 3, pp. 1723-1734, 2011.

[30] E. Tili, J.-J. Michaille, A. Cimino et al., "Modulation of miR-155 and miR-125b levels following lipopolysaccharide/TNF-alpha stimulation and their possible roles in regulating the response to endotoxin shock," Journal of Immunology, vol. 179, no. 8, pp. 5082-5089, 2007.

[31] L. A. O’Neill, F. J. Sheedy, and C. E. McCoy, "MicroRNAs: the fine-tuners of Toll-like receptor signalling," Nature Reviews Immunology, vol. 11, no. 3, pp. 163-175, 2011.

[32] N. Tamassia, M. Castellucci, M. Rossato et al., "Uncovering an IL-10-dependent NF- $\kappa$ B recruitment to the IL-1ra promoter that is impaired in STAT3 functionally defective patients," The FASEB Journal, vol. 24, no. 5, pp. 1365-1375, 2010.

[33] L. Yang, M. P. Boldin, Y. Yu et al., "miR-146a controls the resolution of T cell responses in mice," Journal of Experimental Medicine, vol. 209, no. 9, pp. 1655-1670, 2012.

[34] Y. Ito, S.-C. Bae, and L. S. H. Chuang, "The RUNX family: developmental regulators in cancer," Nature Reviews Cancer, vol. 15, no. 2, pp. 81-95, 2015.

[35] Y. Ito and K. Miyazono, "RUNX transcription factors as key targets of TGF-beta superfamily signaling," Current Opinion in Genetics and Development, vol. 13, no. 1, pp. 43-47, 2003.

[36] W. Heagy, C. Hansen, K. Nieman, and M. A. West, "Evidence for a CD14- and serum-independent pathway in the induction of endotoxin-tolerance in human monocytes and THP-1 monocytic cells," Shock, vol. 19, no. 4, pp. 321-327, 2003.

[37] C. Herrero, X. Hu, W. P. Li et al., "Reprogramming of IL-10 activity and signaling by IFN- $\gamma^{1}$," Journal of Immunology, vol. 171, no. 10, pp. 5034-5041, 2003.
[38] F. Randow, W.-D. Döcke, D. S. Bundschuh, T. Hartung, A. Wendel, and H.-D. Volk, "In vitro prevention and reversal of lipopolysaccharide desensitization by IFN- $\gamma$, IL-12, and granulocyte-macrophage colony-stimulating factor," Journal of Immunology, vol. 158, no. 6, pp. 2911-2918, 1997.

[39] T. K. Varma, T. E. Toliver-Kinsky, C. Y. Lin, A. P. Koutrouvelis, J. E. Nichols, and E. R. Sherwood, "Cellular mechanisms that cause suppressed gamma interferon secretion in endotoxintolerant mice," Infection and Immunity, vol. 69, no. 9, pp. 52495263, 2001.

[40] D. S. Bundschuh, J. Barsig, T. Hartung et al., "Granulocytemacrophage colony-stimulating factor and IFN- $\gamma$ restore the systemic TNF- $\alpha$ response to endotoxin in lipopolysaccharidedesensitized mice," Journal of Immunology, vol. 158, no. 6, pp. 2862-2871, 1997

[41] A. Sica, P. Allavena, and A. Mantovani, "Cancer related inflammation: the macrophage connection," Cancer Letters, vol. 267, no. 2, pp. 204-215, 2008.

[42] A. Sica and A. Mantovani, "Macrophage plasticity and polarization: in vivo veritas," The Journal of Clinical Investigation, vol. 122, no. 3, pp. 787-795, 2012.

[43] E. S. Melo, D. F. Barbeiro, R. Gorjão et al., "Gene expression reprogramming protects macrophage from septic-induced cell death," Molecular Immunology, vol. 47, no. 16, pp. 2587-2593, 2010.

[44] H. Pan, E. Ding, M. Hu, A. S. Lagoo, M. B. Datto, and S. A. Lagoo-Deenadayalan, "SMAD4 is required for development of maximal endotoxin tolerance," The Journal of Immunology, vol. 184, no. 10, pp. 5502-5509, 2010.

[45] G. Curtale, F. Citarella, C. Carissimi et al., "An emerging player in the adaptive immune response: microRNA-146a is a modulator of IL-2 expression and activation-induced cell death in T lymphocytes," Blood, vol. 115, no. 2, pp. 265-273, 2010.

[46] P. Fallah, E. Arefian, M. Naderi et al., "MiR-146a and miR-150 promote the differentiation of $\mathrm{CD}_{13}{ }^{+}$cells into T-lymphoid lineage," Molecular Biology Reports, vol. 40, no. 8, pp. 4713-4719, 2013.

[47] T. Jurado-Camino, R. Córdoba, L. Esteban-Burgos et al., "Chronic lymphocytic leukemia: a paradigm of innate immune cross-tolerance," Journal of Immunology, vol. 194, no. 2, pp. 719727, 2015.

[48] Y. Shao, J. Li, Y. Cai et al., "The functional polymorphisms of miR-146a are associated with susceptibility to severe sepsis in the Chinese population," Mediators of Inflammation, vol. 2014, Article ID 916202, 10 pages, 2014. 


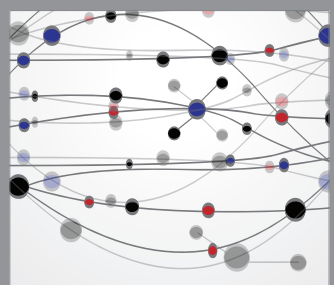

The Scientific World Journal
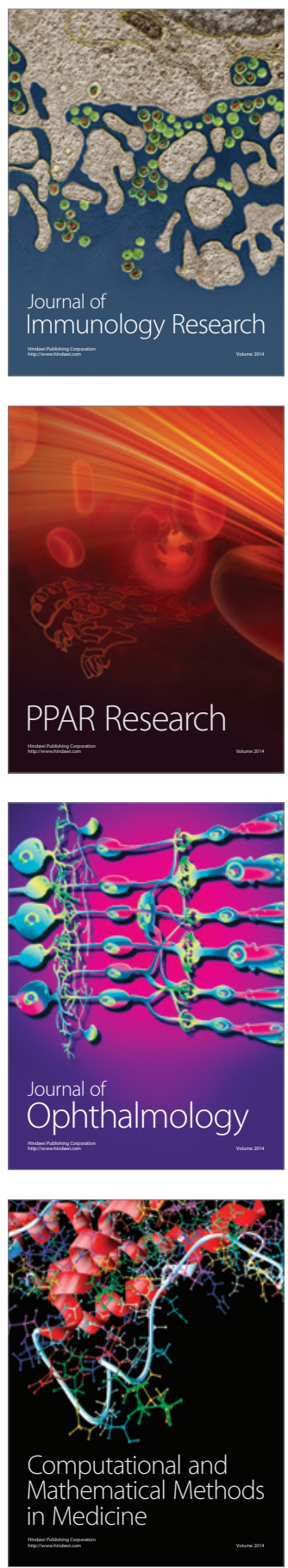

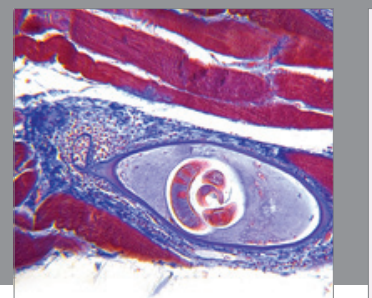

Gastroenterology

Research and Practice
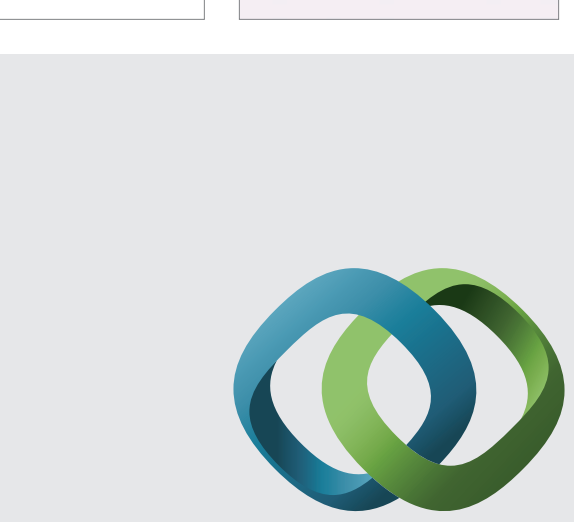

\section{Hindawi}

Submit your manuscripts at

http://www.hindawi.com
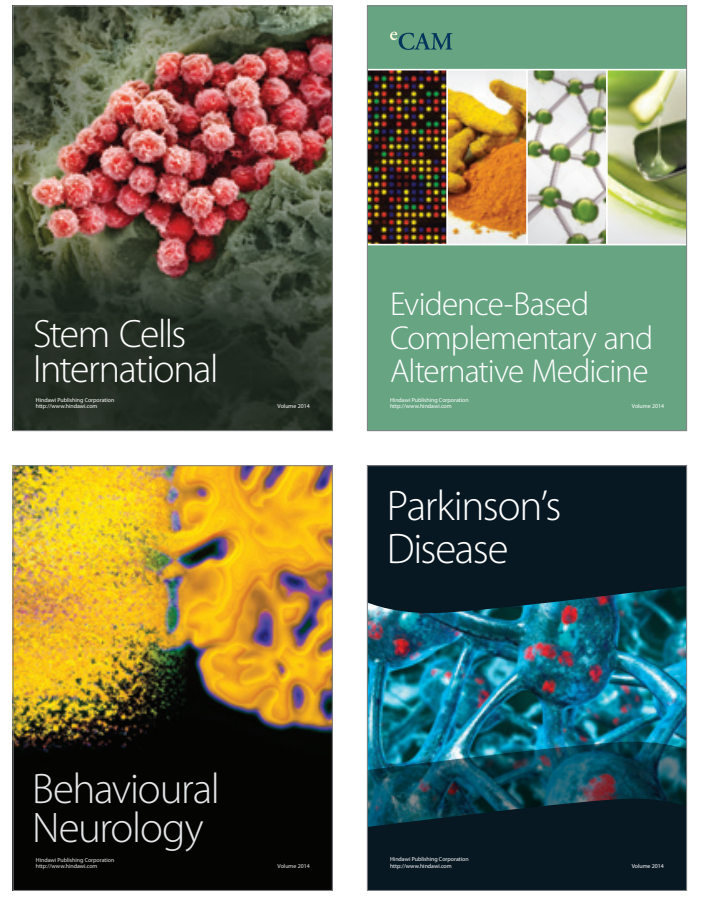
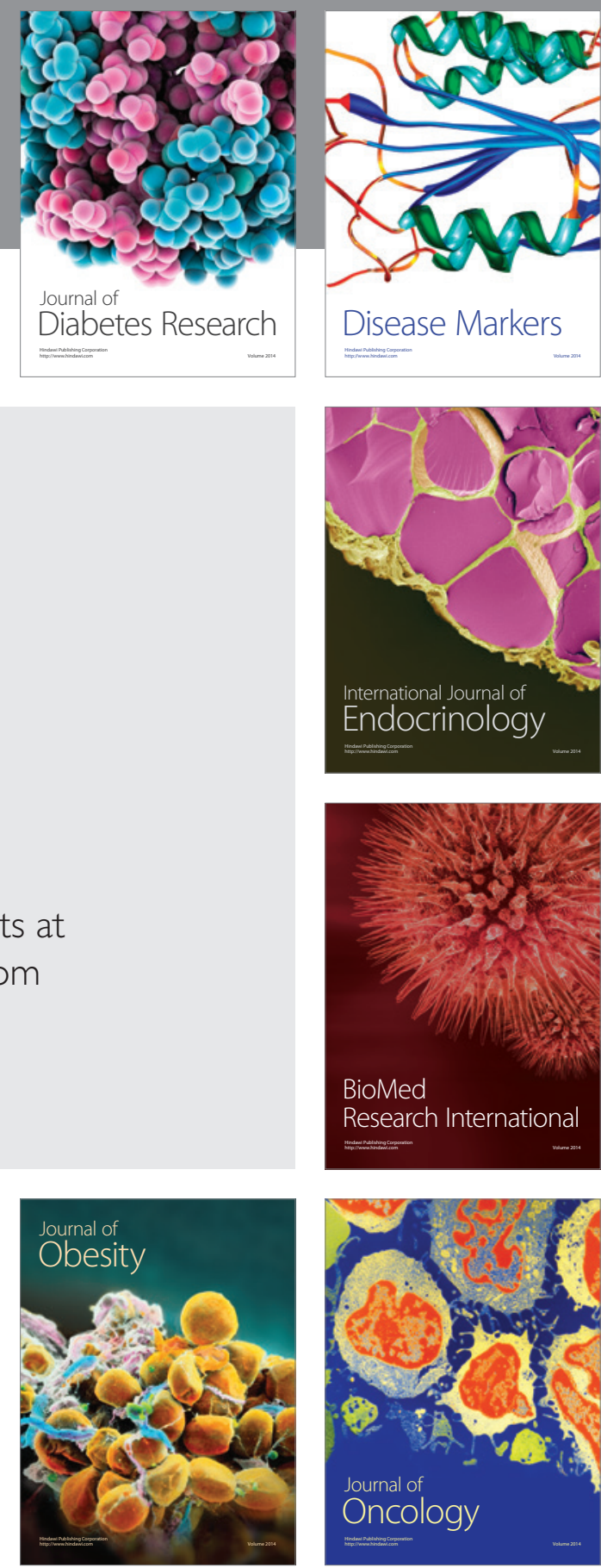

Disease Markers
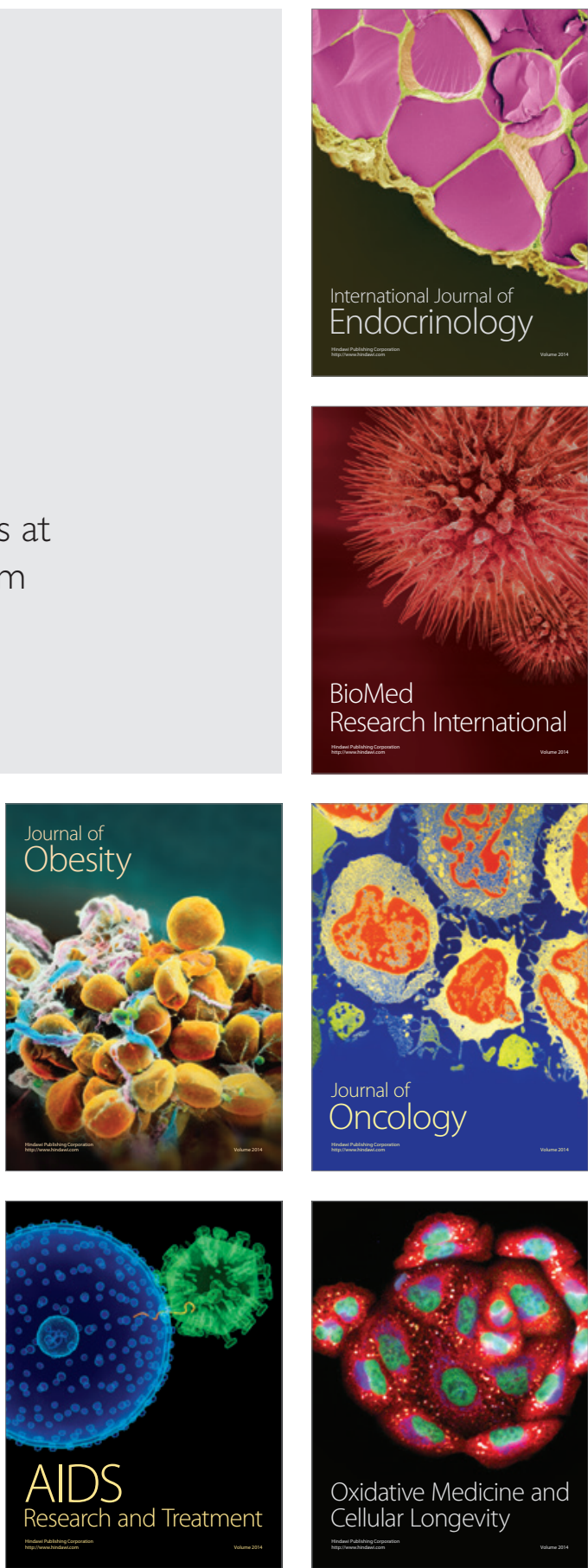